AperTO - Archivio Istituzionale Open Access dell'Università di Torino

\title{
Consequences of Schematism
}

\section{This is the author's manuscript}

Original Citation:

Availability:

This version is available http://hdl.handle.net/2318/59346

since

Published version:

DOI:10.1007/s11097-008-9108-0

Terms of use:

Open Access

Anyone can freely access the full text of works made available as "Open Access". Works made available under a Creative Commons license can be used according to the terms and conditions of said license. Use of all other works requires consent of the right holder (author or publisher) if not exempted from copyright protection by the applicable law. 


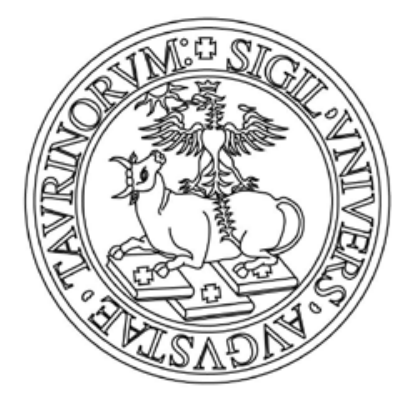

\section{UNIVERSITÀ DEGLI STUDI DI TORINO}

This is an author version of the contribution published on:

Questa è la versione dell'autore dell'opera:

A. Voltolini (2009) Consequences of Schematism, PHENOMENOLOGY AND THE COGNITIVE SCIENCES (ISSN:1568-7759), pp. 135- 150. Vol. 8

DOI 10.1007/s11097-008-9108-0

The definitive version is available at:

La versione definitiva è disponibile alla URL:

http://www.springerlink.com/content/108987/ 


\section{Consequences of Schematism}

\section{Abstract}

In his (2001a) and in some related papers, Tim Crane has maintained that intentional objects are schematic entities, in the sense that, insofar as being an intentional object is not a genuine metaphysical category, qua objects of thought intentional objects have no particular nature. This approach to intentionalia is the metaphysical counterpart of the later Husserl's ontological approach to the same entities, according to which qua objects of thought intentionalia are indifferent to existence. But to buy a metaphysically deflationary approach does not mean to buy an ontologically deflationary approach, according to which we have to accept all the intentional objects there apparently are. Being metaphysically deflationary on intentionalia rather means that from the ontological point of view one must really allow only for those intentionalia for which one is entitled to say that there are such things; typically, for which an ontological proof is available. From metaphysical schematism plus conditional, or partial, ontological committment to intentionalia, further interesting consequences follow. First, this theoretical combination allows one to deal with the 'too-many entities' problem (may one fail to accept an ontological proof for an entity of a given kind if she thinks that the entity we would have to be committed to is an entity of another kind?). Second, it allows one to deal with the 'genuinely true report' problem (how is it that if we exercise mindreading with respect to a somehow deluded person, we want our reports to come out as really, not merely fictionally, true?). 


\section{Consequences of Schematism}

In his (2001a) and in some related papers, ${ }^{1}$ Tim Crane has maintained that intentional objects are schematic entities, in the sense that, insofar as being an intentional object is not a genuine metaphysical category, qua objects of thought intentional objects have no particular nature. This approach to intentionalia is the metaphysical counterpart of the later Husserl's ontological approach to the same entities, according to which qua objects of thought intentionalia are indifferent to existence. But to buy a metaphysically deflationary approach does not mean to buy an ontologically deflationary approach, according to which we have to accept all the intentional objects there apparently are. Being metaphysically deflationary on intentionalia rather means that from the ontological point of view one must really allow only for those intentionalia for which one is entitled to say that there are such things; typically, for which an ontological proof is available. From metaphysical schematism plus conditional, or partial, ontological committment to intentionalia, further interesting consequences follow. First, this theoretical combination allows one to deal with the 'too-many entities' problem (may one fail to accept an ontological proof for an entity of a given kind if she thinks that the entity we would have to be committed to is an entity of another kind?). Second, it allows one to deal with the 'genuinely true report' problem (how is it that if we exercise mindreading with respect to a somehow deluded person, we want our reports to come out as really, not merely fictionally, true?). 
1. From the metaphysical point of view, a longstanding debate in philosophy has concerned the question of the nature of intentional objects, the targets of our thoughts, what our thoughts are directed upon (are of or about, in the traditional terminology). On the one hand, ontologically liberal philosophers, who admit that even in cases like those of a hallucination of Nessie and a conjecture on Vulcan there are nonexistent entities those thoughts are directed upon, have taken that intentionalia are either abstract or merely (im)possible concrete entities. Abstractionists on intentionalia divide moreover themselves in two main subgroups: those who believe that intentionalia are minddependent and those who believe that they are mind-independent entities. According to the first subgroup, moreover, some take intentionalia to be immanent entities of some kind, as originally maintained by Brentano (1874): that is, entities which 'in-exist' in the thoughts directed upon them respectively, or put alternatively, entities which constantly depend for their existence on the specific thoughts that respectively conceive of them, in the sense that not only an intentionale can exist only insofar one such thought exists, but it ceases to exist once that thought ceases to exist as well. Others in that subgroup instead take intentionalia to be artefactual constructions, that is, entites which merely historically depend for their existence on the specific thoughts which originally conceive of them: true enough, an intentionale can exist only insofar as one such thought exists, and it comes into existence only once that thought already exists, but it can go on existing even if that thought no longer exists. ${ }^{2}$ According to the second subgroup, on the contrary, intentionalia are taken to be either set-theoretical entities (typically, property sets) or better, something like Platonic attributes (such as the Bold, or the Beautiful). ${ }^{3}$ (Im)possible concretists on intentionalia instead take them to be 
concrete entities which are either set-correlates ${ }^{4}$ or individuals that exist in merely (im)possible worlds, either as worldbound individuals (i.e., individuals that figure just in one merely (im)possible world) ${ }^{5}$ or as transworld individuals (individuals that figure in all (im)possible worlds). ${ }^{6}$ On the other hand, ontologically intolerant philosophers, who think that our discourse to the effect that our thoughts are directed upon something has to be taken at face value only when this very something is a concrete real entity like George W. Bush or Osama bin Laden, have accordingly said that genuine intentional objects are just such entities. ${ }^{7}$ Many reasons have been provided for and against each of the positions here sketched, yet none of them seem to have hitherto allowed the debate to make a significant step forwards.

In this perhaps discomforting theoretical panorama, Crane’s recent proposal on intentionalia seems rather refreshing. For he takes that neither participant to that debate is right insofar as each takes being an intentional object as a genuine metaphysical category, namely something that individuates a particular kind of entity among others. Yet being an intentional object should rather be conceived as something like being a commodity, namely something that does not individuate a particular kind of entity among others, for entities of different kinds (inanimate as well as animate individuals, concrete as well as abstract things) may be commodities. In other terms, being an intentional object is not a genuine metaphysical category. For in point of fact, any entity whatsoever, of any different kind, may be an intentional object insofar as it simply is a thought-of entity, a target of one's thought. In Crane's own words, this means that intentional objects are schematic objects, i.e. entities that "have no nature of their own" (2001a:16). 
Although Crane does not explicitly put it in this way, one may reverse this metaphysically negative thesis into a more positive thesis. Saying that each intentionale has no particular nature is tantamount to saying that it inherits the nature of the particular thing it actually, i.e. independently of its being thought-of (and necessarily, I may also $\operatorname{add}^{8}$ ), is identical with. For instance, suppose I am thinking of the square root of 4, which in point of fact is an abstract entity. The fact that I am thinking of it does not assign it any particular nature: insofar as it is thought-of, it is just the target of my thought. Yet since, independently of the fact that it is thought-of, it is an abstract entity, in point of fact I am thinking of an abstract entity. Mutatis mutandis, suppose I am thinking of the main root of the largest kauri tree, which in point of fact is a concrete thing. The fact that I am thinking of it does not assign it any particular nature - insofar as it is thought-of, it is just the target of my thought. Yet since, independently of the fact that it is thought-of, it is a concrete entity, in point of fact I am thinking of a concrete entity. And so on.

This metaphysical conception of intentionalia has many theoretical advantages. For on the one hand, it allows one to eschew the Scylla of the ontologically liberal positions, which are all forced to share a dubious representationalist picture of intentional objects. Whether abstract or concrete (im)possible entities, intentionalia are for liberals the immediate objects to which one's mind is directed, so that the mind can reach real concrete entities only through the intentionalia's veil. But on the other hand, schematism also allows one to free herself from the Carybdis of the ontologically intolerant positions. These seem to go against commonsense in apriori denying that one can literally think of any entity whatsoever, independently of the kind of thing it is, 
hence in apriori denying that one can literally think also of the entities which are the hardest to swallow, such as the (nonexistent) golden mountain or the (necessarily nonexistent) round square.

Yet this is not the only merit of this position. Suppose we accept a distinction that has recently become rather customary between metaphysics, as the discipline which aims at studying the nature of a (kind of) thing, provided that there is any such thing, and ontology, as the discipline which focusses on whether there are things of a certain kind in the general inventory of what there is, i.e. on whether, à la Quine, one can quantify over those things. ${ }^{9}$ In other terms, let us accept that it is one thing to assess what nature a certain (kind of) thing possesses, quite another to see whether there are entities of that kind, which is to say, whether that kind is instantiated. ${ }^{10}$ Once we accept this distinction, we can easily see that being metaphysically deflationary on intentional objects, as Crane's position can be summarised as being, does not entail being ontologically deflationary on such entities, in the sense of trivially admitting in one's ontology whatever intentional object one is apparently committed to insofar as one appears to think of that object. ${ }^{11}$ Granted, one may say that Crane's position on intentionalia is the metaphysical counterpart of the later Husserl's ontological position on such entities. Insofar as they are targets of our thoughts, intentionalia are indifferent to existence, in the sense that as regards the fact of whether any intentionale whatsoever belongs to the general inventory of what there is, nothing can be said of it from its being thought-of: one can put that ontological fact into brackets, by exercising phenomenological epoché on it. But even if one can reasonably ascribe this ontological perspective to a metaphysical deflationist on intentionalia, this does not mean that 
metaphysical deflationism is ontologically deflationary on such entities. As we saw, ontological deflationism on intentionalia means rather to take for ontologically justified as regards intentionalia whatever seems to be the case given the fact that our thought appears to be directed upon those entities. Thus, suppose that one actually endorses schematism, i.e. metaphysical deflationism, on intentionalia. Moreover, consider schematism in his positive rather than in his negative formulation, namely consider the claim that for any intentionale, what it really is depends on what kind of thing the thing it is actually identical with is. What rather follows from all this is that from the ontological point of view, no general committment to intentionalia can be provided, but just a specific committment to those intentionalia which are identical with entities of a kind for which an ontological proof is available, i.e. for which we can legitimately say that there are things of that kind. In a nutshell, we are not committed to intentionalia in general, but just to some of them, those which are actually such that there really are things of that kind; metaphysical schematism on intentionalia only entails conditional, or partial, committment about such entities. ${ }^{12}$

Let me make some examples. Suppose that a certain intentionale is in point of fact identical with a certain abstract mind-independent entity such as a number. Suppose e.g. that I am thinking of the square root of 4, which in point of fact is a number, the number Two. Then, in order to accept that there really is such an intentional object, one has preliminarily to accept (typically, by means of an ontological proof) that there are numbers, i.e. that there are entities of that particular categorical kind. ${ }^{13}$ Nothing changes if we suppose that a certain intentionale is in point of fact identical with a fictum. Suppose e.g. that I am thinking of Ulysses, which in point of fact is a fictional character. 
Then, in order to accept that there really is such an intentional object, one has preliminarily to accept (typically, by means of an ontological proof) ${ }^{14}$ that there are fictional entities. And so on. But now suppose that a certain intentionale is in point of fact identical with a certain indeterminate entity, i.e. an entity for which it is indeterminate whether it is identical with itself. Suppose e.g. that I am thinking of Indy, the thing which is such that it is indeterminate whether it is the same as Indy itself. And suppose that one has no proof as to the fact that there really are indeterminate objects, or better, suppose that one has a proof to the contrary, that is, suppose that one can prove that there really are no such things. ${ }^{15}$ If this is the case, then in this situation it only seems that there is an intentional object, that there is something I am thinking of; in point of fact, my impressions notwithstanding, I am thinking of nothing. ${ }^{16}$

2. If metaphysical schematism on intentionalia only entails conditional, or partial, ontological committment about such entities, then one has to be ready to provide an answer as to the following question. If it turns out that there really is no such thing as a certain intentional object, for that intentionale belongs to a category for which one can prove that there really are no instantiations, what the thought which was originally supposed to be about 'it' turns out to be?

Following again Crane, I take that the most plausible answer to this question is to say that that thought merely has a certain intentional content. ${ }^{17}$ For instance, take the case of a thought apparently directed upon Indy, the vague entity I introduced before. As Indy is a vague entity and we can supposedly rely on a proof as to the fact that there are no such things as vague entities, it cannot be the case that that thought is really 
about Indy, for there is no such a thing. Rather, that thought will have something like an Indy-ian intentional content. To be sure, this shows that that thought has a different structure from that it was originally supposed to have: instead of being directed upon an intentional object, it has a certain intentional content. That is, that thought is not such that is connected via a certain intentionality relation with an intentional object such that (it is proved that) there is such an object. Instead of instantiating the relational property of being directed upon an intentional object, that thought instantiates the property of having an intentional content. Yet this does not yet mean that that thought has a nonrelational structure, unless one is able to prove that the property of having an intentional content is a monadic property for a thought to have, and not another relational property whose relational component is precisely a certain intentional content. ${ }^{18}$ Yet it is very hard to prove that such a property is monadic rather than relational. Let me explain why.

As is widespreadly acknowledged, the best way to run for a monadic account of the property of having an intentional content is to appeal to the adverbialist approach to intentionality ${ }^{19}$ in its most plausible version, i.e. the one according to which the adverb which is supposed to express the monadic property in question is a thought-, not a subject-, modifier. ${ }^{20}$ Suppose a subject $\mathrm{S}$ is thinking of O. Assuming moreover that it turns out that there is no such a thing as $\mathrm{O}$, according to this version of adverbialism S's thought merely has the property of having a certain intentional content monadically interpreted; that is, her thought is modified O-wise, or, as many say, is O-ly (and not: she is-thinking-O-ly, as one would have to say if one appealed to the other version of adverbialism, that makes the adverb a subject-modifier). 
One might think that the reason why I take thought-modifier adverbialism to be better than subject-modifier adverbialism is that the latter would hardly account for the idea of that having an intentional content is a monadic property of a thought, as is intuitively the case. For trivially, the monadic property subject-modifier adverbialism involves is a property not of the thought but of the thought's bearer, its subject. But the main reason for the claim that thought-modifier adverbialism can fare better than subject-modifier adverbialism is that there is for it a way of solving problems that subject-modifier adverbialism can hardly face. Unfortunately, however, it remains that the hardest problem for subject-modifier adverbialism is unsolved for thought-modifier adverbialism either. Let us see.

From Jackson (1975) onwards, one normally assumes that there is a hardly surmountable obstacle for adverbialism, namely the fact that adverbialists cannot solve the following two problems at the same time. Intuitively, it is one thing to say:

(1) S thinks of a pink elephant and of a red dragon

and quite another to say:

(2) S thinks of a red elephant and of a pink dragon

insofar as the two reports ascribe the subject $\mathrm{S}$ thoughts which are different for intuitively their content is such. Yet for subject-modifier adverbialism the two reports collapse into saying: 
(3) S thinks-pinkly-elephantly-redly-dragonly

which does not pick up the difference between the two thoughts in question. Apparently thought-modifier adverbialism can account for this difference, for it may say that the first sentence has to be paraphrased as:

(1t-a) S thinks pink-elephantly and red-dragonly

while the second sentence has to be differently paraphrased as:

(2t-a) S thinks red-elephantly and pink-dragonly.

Yet if a thought-modifier adverbialist runs that way, it remains hard for her to simultaneously account for the fact that one can intuitively infer the further sentence:

(4) S thinks of an elephant

from:

(5) S thinks of a pink elephant. 
For adverbialists cannot here appeal to a compositional account of these sentences' structures, which is what normally allows one to draw that inference. As a matter of fact, the latter inference cannot be accounted for by subject-modifier adverbialism, which is forced to read the two sentences respectively as:

(4s-a) S thinks-elephantly

(5s-a) S thinks-pinkly-elephantly

where the two predicates "thinks-pinkly-elephantly" and "thinks-elephantly" stand for utterly different properties. Yet again, if for the thought-modifier adverbialist (5) means the same as:

(5t-a) S thinks pink-elephantly

where the phrase "pink-elephantly" stands for a certain monadic property of a thought, how can she be allowed to infer from that sentence her paraphrasis of (4),

(4t-a) S thinks elephantly

where the adverb "elephantly” stands for another monadic property of a thought?

Now, the typical answer thought-modifier adverbialists provide to this trouble is to say that there is some internal connection between the property the adverb "elephantly" stands for and the property the phrase "pink-elephantly" stands for; for 
instance, a determinable-determinate relation. ${ }^{21}$ This allows a thought-modifier adverbialist to say that whenever a thought is modified pink-elephantly, it is also modified elephantly, hence one may infer (4t-a) from (5t-a).

If one accepts this reply, then there is a way for thought-modifier adverbialism to simultaneously account both for the difference between (1) and (2) and for the inference from (5) to (4). Yet even if one accepted this reply, the real trouble for thought-modifier adverbialism is that it is unable to deal with a further, more basic, problem. This is the reformulation of an analogous problem that affects subjectmodifier adverbialism. As Fodor notoriously summed up against subject-modifier adverbialism, if reports such as (4) and:

(6) S thinks of a dragon

are respectively paraphrased as (4s-a) and as:

(6s-a) S thinks-dragonly

then the intuitive idea that what is predicated of $S$ in those reports are two different species of one and the same general kind of property, thinking of something, seems completely to vanish. For in that reconstruction, "thinks-elephantly" and "thinksdragonly” respectively stand for completely different properties; as Fodor puts it, they are different primitive predicates. ${ }^{22}$ Of course, a thought-modifier adverbialist can easily account for this problem, insofar as she paraphrases the two sentences as (4t-a) and as: 
(6t-a) S thinks dragonly

respectively, where thinking elephantly and thinking dragonly are precisely two different species of a very general property of thinking of something. Yet the very same problem arises for the thought-modifier adverbialist in a different form. Intuitively, in:

(7) S thinks of Indy

(8) T waits for Whack

the different intentional states which are mobilised by these reports share one and the same intentionality property: the first is a thought of Indy, the vague entity I have introduced before, while the second is an expectation of Whack, the impossible horse which is all black and all white at the same time. ${ }^{23}$ As it is quite likely that there really are neither vague nor impossible entities, the intentionality property that (7)-(8) mobilise is the property of having an intentional content that is instantiated by the intentional states these sentences involve. Yet if (7)-(8) are respectively reconstructed by the thought-modifier adverbialist as:

(7t-a) S thinks Indy-ly

(8t-a) T waits Whack-ly 
the idea that the two involved intentional states share the above intentionality property vanishes. For what can ground the idea that the two states have something in common that they do not share with the states mobilised by sentences like:

(9) S thinks seriously

(10) T waits makebelievedly

etc.? True enough, as far as (7)-(8) are concerned, a thought-modifier adverbialist may sensibly guess that she is predicating of the intentional states involved by these sentences a property that corresponds to a suitable modification of those states. But that adverbialist is not justified in saying that that sentential pair singles out modifications of intentional states which have something in common between each other and yet nothing, or nothing relevant, in common with the modifications of intentional states singled out by the second sentential pair (9)-(10). For one thing, here the thought-modifier adverbialist cannot say that being Indy-wise and being Whack-wise, but not being serious and being make-believe, are determinates of same determinable. ${ }^{24}$ Or, if she says something along those lines, she is implicitly appealing to a previous grasp of the intentionality property of having an intentional content which should be precisely forbidden to an adverbialist, insofar as she attempts to precisely reconstruct that property in terms of an adverbialist account. ${ }^{25}$ Put in another way, it should turn out of the very specific properties of being Indy-wise and being Whack-wise that they have something in common relevant for intentionality. Yet there is no commonality which turns out of those properties that it may not also turn out of the properties of being 
serious and being make-believe; but then whatever turns out of all these properties is too generic in order for it to be the intentionality property of having an intentional content monadically reconstrued the adverbialist is looking for. ${ }^{26}$

In the end, thus, one can positively put things in this way. On the one hand, thoughts apparently directed upon intentionalia which are identical to things for which it has been proved that there are things of that kind really stand in a certain intentionality relation, reference intentionality or aboutness, with those things. On the other hand, thoughts which are apparently directed upon intentionalia which are identical to things for which it has not been proved that there are things of that kind, or better, which are identical to things of a kind for which it has been proved that there are no things of that kind, merely have intentional contents. This actually means that those thoughts stand in a different intentionality relation, say aboutness 2 , with intentional contents. ${ }^{27}$ Whatever they are, intentional contents therefore turn out to be full-fledged entities as much as those intentional objects for which it has been proved that there are such objects. Hence, aboutness 2 is relational as much as aboutness is, for it also puts a thought in connexion with an entity. Yet it is a different relation from aboutness, for its relatum is an entity of a different kind. That is, its relatum is not a schematic entity which is such that its nature is given case by case and that there really is one such thing, as any genuine, not merely apparent, intentional object is. Rather, it is an entity whose nature typically is that of an abstractum - the nature which ontologically tolerant sustainers of intentionalia erroneously ascribed to intentional objects themselves: e.g., (correlates of) sets of properties, Platonic attributes, etc.. One is indeed forced to conclude that, since intentional contents are what turns out to be there once those merely 
apparent schematic intentional objects are removed from our overall domain, they are not schematic entities, but rather have a genuine metaphysical nature. All in all, this result allows a schematist to retain a sufficiently uniform picture of intentionality that, although it splits into two different relations, has an overall relational nature. ${ }^{28}$

3. Once metaphysical schematism on intentionalia meshes itself with a partial ontological committment to these entities - to repeat, there only are those intentionalia which are identical with things such that it has been proved that there are things of that kind - some further interesting consequences follow, that show once more how this position is theoretically fruitful. First, schematism allows one to deal with the 'toomany entities' problem (may one fail to accept an ontological proof for an entity of a given kind if she thinks that the entity we would have to be committed to is an entity of another kind?). Second, it allows one to deal with the 'genuinely true report' problem (how is it that if we exercise mindreading with respect to a somehow deluded person, we want our reports to come out as really, not merely fictionally, true?) Let me conclude this paper by considering the two issues in order.

To begin with, the 'too many entities' problem may be illustrated by means of examples. Suppose that you tell a desperate child who has just discovered that Santa Claus does not exist that he does not have to despair, for there nevertheless is such a thing as Santa Claus. In point of fact, Santa Claus is a fictional character and luckily enough we've got a proof that there are such things as ficta. Would the child's most likely angry reaction (“but that's not the Santa Claus I was waiting for!”) be justified? Or analogously, suppose that you tell a desperate St. Anselm who has just discovered 
that his proof of God's existence does not work that he does not have to despair, for there nevertheless is such a thing as God. For God is a fictional character and in point of fact we've got a proof that there are such things as ficta. Would St. Anselm's most likely annoyed reaction (“but that's not the God I was striving at proving!”) be justified?

In more general terms, the problem is: may one attempt at proving that there are things (such as Santa Claus, God ...) independently of what the nature of these things turns out to be? Or does the fact that a thing is ascribed a certain nature determines a distinction in the number of things as to which one tries to prove that there are such things? If Santa Claus (God, etc.) is a thing of a certain kind and not of another kind, then isn't a proof as to the fact that there is such a thing eo ipso a proof that there is a thing of that very kind, so that, if one assigned Santa Claus another kind, then a proof as to the fact that there is such a thing cannot be a proof as to the fact that there is the above original thing, but rather, it is a proof as to the fact that there is quite another one?

This problem is particularly pressing if, as I did, one accepts the aforementioned distinction between metaphysics, as the doctrine that aims at studying the nature of certain things, provided that there are any, and ontology, as the doctrine that aims at seeing whether there really are such things. On the one hand, if the answer to the ontological problem were completely independent of the answer to the metaphysical problem, then the above persons' reaction would simply be illegitimate: whatever an entity turns out to be from the metaphysical point of view, an ontological proof is a proof of the fact that there is such an entity. Yet on the other hand, if the answer to the ontological problem were not completely independent of the answer to the metaphysical problem, in the sense that in order to provide an answer as to the problem of whether 
there really is a certain entity one first has to give a specific answer as to the metaphysical problem of what kind of thing that entity is, then the persons' reaction would not be unjustified. As a matter of fact, it may well seem that if Santa Claus (God) turns out to be a fictional entity rather than a concrete (necessary) supernatural entity, then the ontological fact that there is such a thing, i.e. a thing of that kind, is not the fact that one would have expected before that discovery. This putative fact would rather have been the fact that there were another entity, i.e. a thing of another kind.

It is here that intentional objects qua schematic objects enter the stage. Only if the object of debate is originally a schematic intentional object we share with the desperate person - we agree that we are thinking of the same thing - then, once it is moreover established which nature that intentionale really possesses independently of the fact that it is thought-of, and besides, a proof as the fact that there really are things of that kind is available, the person cannot legitimately protest that what we have proved is that there is another thing. Thus, suppose that the child (St. Anselm) agrees with us that by debating about Santa Claus (God) we are thinking of the same thing, a certain schematic intentionale. Now, if that intentionale turns out to be identical with a thing of a certain kind (the Santa Claus of our thought turns out to be identical with a fictional object), and moreover, if a proof as to the fact that there really are things of that kind is available (there is a proof as to the fact that there are fictional objects), then the child (St. Anselm) cannot be justified in saying that that proof is a proof as to the fact that there is another thing. The child (St. Anselm) simply turns out to be someone who does not know what is the nature of the entity which he and us are both focusing and for which we have proved that there really is such a thing. This is to say, the child 
(St. Anselm) turns out to simply have erroneous beliefs as regards the real nature of the thing that intentionale is actually identical with: he misbelieves that Claus is a concrete actually existing natural entity (St.Anselm misbelieves that God is a concrete necessarily existing supernatural being), whereas in point of fact Claus (God) is a fictional entity. But if the child (St. Anselm) and us shared no schematic intentional object, there would be no chance for us to show that the child (St. Anselm) is wrong in thinking that we have proved that there is another thing.

Let us now pass to the 'genuinely true report' problem. Suppose we are confronting with a deluded person that erroneously thinks he is facing an entity, perhaps for he is unawarely hallucinating it, or for it actually is a false posit of his. How can we be justified in holding that, when by exercising our mindreading capacity we say that that person is believing that that very entity is $F$, what we say is really true, not merely fictionally true? For instance, suppose we are considering an ancient Greek telling that Zeus lives on Mount Olympus, or a contemporary Scot telling that Nessie is swimming in Loch Ness, or even the $18^{\text {th }}$ century astronomer Leverrier telling that Vulcan lies between Mercury and the Sun. Intuitively, neither of the entities involved by these tales exist. Now, it is quite easy to ascribe sentences like:

(11) The ancient Greeks believed that Zeus lived on Mount Olympus

(12) That Scot believes that Nessie is swimming in Loch Ness

(13) Leverrier believed that Vulcan lied between Mercury and the Sun 
a fictional truth. We simply have to make believe both that there are things such as Zeus, Nessie and Vulcan and that the relevant subjects have beliefs on these things. As a result, the above sentences turn out to be true in the world of that make-believe imagination, a world such that its domain contains such things and those people have the above beliefs. But we have also the impression that the above sentences are not only fictionally, but also really, true. It is indeed hard to deny that the above subjects really have certain intentional states; it is not only that we make believe that they have such states. To dramatise the issue, consider a first-person case. I'm pretty sure that I'm now believing that there is a computer in front of me lying on a table in my room. I'm definitely not in the situation in which, by telling someone a story, I could be legitimately said to make believe that once upon a time, things stood in the way my story goes. Moreover, suppose that it turned out that I'm suffering from a terrible hallucination: there is no computer etc. in front of me. So, I would be precisely in the same boat as the deluded persons I was just describing. And yet, how could it be that all of us believe something, given that all the things apparently involved in our states do not exist? If all of us really had beliefs, these beliefs would have to have a singular content, for these states seem to be addressed to particular individuals. Yet since those individuals do not exist, how can we really have such beliefs? ${ }^{29}$

Conforming to what I said above, this question can be answered in two steps. First, we have to consider those deluded thoughts as prima facie directed upon certain schematic intentionalia. Second, we must either have at our disposal a proof that there are things of kinds such that those intentionalia are identical with these things, so that we can take those thoughts as really directed upon the intentionalia in question, or, if 
there is no such proof (even better, if there is a proof to the contrary), we have to single out the intentional contents those thoughts are rather related with. As a result, the relevant ascription will have real truthconditions which will moreover be either singular or general truthconditions. In both cases, "S believes that $\mathrm{O}$ is $\mathrm{F}$ " is true iff " $\mathrm{O}$ is $\mathrm{F}$ " is true at such worlds: with the semantical interpretation we assign to that embedded sentence, that sentence is evaluated as true with respect to the worlds compatible with S's belief - the belief-worlds. Yet in the first case, "S believes that $\mathrm{O}$ is F" is true iff $\mathrm{S}$ believes that a certain intentionale $\mathrm{O}$ is $\mathrm{F}$, namely iff in the worlds compatible with S's belief, that very entity $\mathrm{O}$ is $\mathrm{F}$. Whereas in the second case, " $\mathrm{S}$ believes that $\mathrm{O}$ is $\mathrm{F}$ " is true iff $\mathrm{S}$ believes that the thing which O-S is F, namely iff in the worlds compatible with S's belief, the thing which O-s there is F.

Besides, if neither of these options were the case, the belief ascription in question could only possess pretend singular truthconditions. The ascription is fictionally true iff in the world of the pretence, $\mathrm{S}$ believes that that object he intends there is $F$, i.e. " $\mathrm{S}$ believes that $\mathrm{O}$ is $\mathrm{F}$ " is true in that world: with the semantical interpretation given to it in the world of pretence, that sentence is evaluated as true with respect to that world. ${ }^{30}$

Let me go back to the previous cases. Suppose we agree that Zeus is a schematic intentional object. Moreover, suppose first that we establish that such an intentional object is identical with a certain fictional entity, and second, that we have a proof as to the fact that there are fictional objects. Then, (11) has the following real singular truthconditions: that sentence is true iff the ancient Greeks believed that that intentionale lived on Mount Olympus, namely iff in the belief-worlds, that entity, Zeus, 
lives on Mount Olympus (i.e. “Zeus lives on Mount Olympus”, where “Zeus” refers to that intentionale, is true at such worlds). Analogously with Vulcan as regards (13), in the hypothesis that such an intentionale is a possibile - i.e. an object that even though it does not actually exist, in a certain first-order sense of the term "to exist", it might have existed - and we have a proof as to the fact that there are possibilia, as well as with Nessie, which may be identified either with a possible or with an imaginary object, where imaginary objects are species of ficta, as regards (12). But now take Canden, the wooden cannon which is made of steel, ${ }^{31}$ and consider the sentence:

(14) Twardowski believed that Canden hardly fires.

Again, let us agree that Canden is a schematic intentional object, but let us assume this time that that intentionale is identical with an impossible object and that we do not have a proof that there are impossibilia or better, we have a proof that there are no such things. If this is the case, then what actually happened with Twardowski was that his thought was merely apparently directed upon an intentional object, but had rather a mere Canden-ian intentional content. Hence, the real truthconditions of (14) cannot but be the following general ones: that sentence is true iff Twardowski believed that the thing which Candens hardly fires, namely iff in the belief-worlds, the thing which Candens there hardly fires.

If the above were not the case, then the aforementioned sentences could only have fictional truthconditions: that is, regardless of which ascription we actually consider among (11)-(14), the ascription is fictionally true iff in the world of the 
pretence, S (the Greeks, etc.) believes that that object he intends there (Zeus, etc.) is $F$ (lives on Mount Olympus, etc.), i.e. " $\mathrm{S}$ (the Greeks, etc.) believes that $\mathrm{O}$ (Zeus, etc.) is $\mathrm{F}$ (lives on Mount Olympus, etc.)" is true in that world. Thus, the only possibility for those sentences to have real truthconditions is to appeal first to schematic intentionalia and then, depending on whether there really are such intentionalia or not, to mobilise in those truthconditions either an intentional object or an intentional content.

I stress the above point, for theoretically speaking, there is a third possibility for assigning those sentences real truthconditions, i.e. to admit not only that the relevant ascription has such truthconditions but also that they involve a context-shifting epistemic operator; namely, one such ascription is true iff S believes that, in worlds like that of the pretence, that object he intends there is $F$ (i.e. iff " $\mathrm{O}$ is F" is true in the belief worlds, including the world of the pretence). ${ }^{32}$

But this possibility suffers from a serious implausibility. For it means that being the kernel sentence fictionally true, its being true in a pretend world, is sufficient for the ascription to be really true. Which is to say: for a sentence to be true in the actual world, with the semantic interpretation it is given in that world, it is enough that an(other) sentence is true in another world, the world of the pretence, with the semantic interpretation it is given in that world. But, as Kripke originally taught us, ${ }^{33}$ no semantic matters concerning the actual world may depend on semantic matters concerning another world. Nothing of what the inhabitants of another world establish from a semantic point of view may affect what we, in our world, establish from that point of view. 
The morale of this paper is thus the following. If intentionalia are metaphysically schematic objects, then the commonsensical claim that thoughts are directed upon intentionalia can turn out at least to be partially legitimate: that is, whenever those entities are actually (and necessarily) identical with entities of a certain categorical kind and we can justifiably say that there are entities of this kind. Definitely, one such proof can be provided for prima facie suspicious entities, e.g. for abstracta, ficta, and possibilia. Yet only if it could be provided also for utterly implausible entities, e.g. for indeterminata and impossibilia, the above commonsensical claim could be fully vindicated. ${ }^{34}$

\section{Bibliography}

Author (2005) On the Metaphysics of Internalism and Externalism. Disputatio 18: 127-150.

Author (2006a) Are There (Nonexistent) Intentionalia?. Philosophical Quarterly 56: 436-441.

Author (2006b) How Ficta Follow Fiction. A Syncretistic Account of Fictional Entities. Springer, Dordrecht.

Author (2006c) Reference intentionality is an internal relation. In: Miguens, S. et al (eds) Analyses Proceedings of the Second National Meeting for Analytic Philosophy. Facultade de Letras da Universidade do Porto, Porto 2006: 66-78.

Author (2007) How to Allow for Intentionalia in the Jungle. Russell 27: 86-105.

Adams R. (1981) Actualism and Thisness. Synthese 49: 3-41.

Brentano F. (1874) Psychologie vom empirischen Standpunkt, Band I. F. Meiner, Hamburg; trans. A.C. Rancurello et al, Routledge, London $1995^{2}$.

Castañeda H-N. (1989). Thinking, Language, and Experience. University of Minnesota Press, Minneapolis. 
Chisholm R.M. (1957) Perceiving. A Philosophical Study. Cornell University Press, Ithaca, N.Y.

Chisholm R.M. (1996) A Realistic Theory of Categories. Cambridge University Press, Cambridge.

Colyvan M. (2004) Indispensability Arguments in the Philosophy of Mathematics.I in Zalta E. (ed)

Stanford Encyclopedia of Philosophy, http://plato.stanford.edu/entries/mathphil-indis/

Crane T. (2001a) Elements of Mind. Oxford University Press, Oxford.

Crane T. (2001b) Intentional Objects. Ratio 14 (2001): 336-349.

Crane T. (2003) The Intentional Structure of Consciousness. In: Jokic A., Smith Q. (eds) Consciousness: New Philosophical Perspectives Oxford University Press, Oxford: 33-56.

Ducasse C. J. (1942) Moore’s 'The Refutation of Idealism’. In: Schlipp P. (ed) The Philosophy of G.E. Moore. Northwestern Press, Evanston.

Evans G. (1978) Can There Be Vague Objects?. Analysis 38: 208.

Evans G. (1982) The Varieties of Reference. Clarendon Press, Oxford.

Fodor J.A. (1981) Propositional Attitudes. In: Representations, The MIT Press, Cambridge MA: 177-203.

Gracia J.J.E. (1999) Metaphysics and Its Tasks. SUNY Press, Albany.

Haldane J. (1989) Brentano's Problem. Grazer Philosophische Studien 35: 1-32.

Husserl E. (1984) Logische Untersuchungen, Husserliana XIX/1-2, Band II, Untersuchungen zur Phänomenologie und Theorie der Erkenntnis, M. Nijhoff, Den Haag; transl. (from the $1922^{3}$ edition, Niemeyer, Halle) J.N. Findlay, Routledge and Kegan Paul, London 1970.

Ingarden R. (1931) Das literarische Kunstwerk. Niemeyer, Tübingen; transl. G.G. Grabowicz, Northwestern University Press, Evanston 1973.

Jackson F. (1975) On the Adverbial Analysis of Visual Experience: Metaphilosophy 6: 127-135.

Johannson I. (1989) Ontological Investigations. Routledge, London.

Kriegel U. (2007) Intentional Inexistence and Phenomenal Intentionality. Philosophical Perspectives 21, 307-340.

Kripke S. (1971) Identity and Necessity. In: Munitz M.K. (ed) Identity and Individuation. New York University Press, New York: 135-164.

Kripke S. (1980) Naming and Necessity. Blackwell, Oxford. 
Kroon F. (2005) Beliefs about Nothing in Particular. In: Kalderon M.K. (ed) Modal Fictionalism. Oxford University Press, Oxford: 178-203.

Lewis D. (1986). On the Plurality of Worlds. Blackwell, Oxford.

Parsons T. (1980). Nonexistent Objects. Yale University Press, New Haven.

Priest G. (2005) Towards Non-Being: the Logic and Metaphysics of Intentionality. Clarendon Press, Oxford.

Quine W.V.O. $\left(1961^{2}\right)$ On What There Is. In: From a Logical Point of View. Harper \& Row, New York: $1-19$.

Rapaport W.J. (1978) Meinongian Theories and a Russellian Paradox. Noûs 12: 153-180.

Recanati F. (2000) Oratio Obliqua, Oratio Recta. The MIT Press, Cambridge MA.

Schiffer S. (2003) The Things We Mean. Clarendon Press, Oxford.

Searle J.R. (1983) Intentionality. Cambridge University Press, Cambridge.

Thomasson A.L. (1999). Fiction and Metaphysics. Cambridge University Press, Cambridge.

Twardowski K. (1982) Zur Lehre vom Inhalt und Gegenstand der Vorstellungen. Philosophia Verlag, München/Wien.

Tye, M (1984) The Adverbial Approach to Visual Experience. The Philosophical Review 93: 195-225.

Walton, K.L (1990) Mimesis as Make-Believe. Harvard University Press, Cambridge MA.

Zalta E.N. (1988) Intensional Logic and the Metaphysics of Intentionality. The MIT Press, Cambridge MA.

${ }^{1}$ Cf. Crane (2001a, 2001b).

${ }^{2}$ For this position, originally defended by Ingarden (1931), cf. paradigmatically Thomasson (1989).

${ }^{3}$ A typical defender of the latter position is Zalta (1988).

${ }^{4}$ For this position, cf. respectively Castañeda (1989), Parsons (1980), Rapaport (1978).

${ }^{5}$ As implicitly suggested in Lewis (1986).

${ }^{6}$ Cf. Priest (2005).

${ }^{7}$ The early Husserl (1984) is probably the most famous defender of this idea. For a famous contemporary reprise of this position, cf. Searle (1983). 
${ }^{8}$ Following notoriously Kripke (1971), I believe in the thesis of identity's being a necessary relation of an object with itself.

${ }^{9}$ On this way of addressing ontological matters, cf. notoriously Quine $\left(1961^{2}\right)$.

${ }^{10}$ For this distinction between metaphysics and ontology, cf. e.g. Chisholm (1996), Gracia (1999), Johannson (1989), Thomasson (1999).

${ }^{11}$ For a thorough defence of a deflationary position in ontology (at least as regards entities such as properties and propositions), cf. Schiffer (2003). On this concern note that, although in the case of intentionalia there are no 'something-from-nothing' transformations that lead to the postulation of such entities, as according to Schiffer is the case with properties and propositions (like "Fido is a dog iff Fido has the property of being a dog”), an ontological deflationist on intentionalia may claim that the very same ordinary language argument that for Schiffer further supports the existence of the latter entities also supports the existence of the former entities. That is, if from "Bush believes that Jesus is resurrected but Osama disbelieves that" one can seemingly infer "There is something, namely a proposition, that Bush believes and Osama disbelieves", then from "The Scots like Nessie but the Irish dislike it" one can seemingly infer "There is something, namely an intentional object, that the Scots like and the Irish dislike”. But this strategy is dubious, for it may also lead to the opposite ontological result. That is, if one has qualms as regards intentionalia, the above similarity in inferring existential generalisations may lead her to reject properties and propositions as well.

${ }^{12}$ For more on this, cf. Author (2006a).

${ }^{13}$ On ontological arguments for numbers, cf. e.g. Colyvan (2004).

${ }^{14}$ For which, cf. e.g. Thomasson (1999), Author (2006b).

${ }^{15}$ Cf. notoriously Evans (1978).

${ }^{16}$ Crane admits that ontological committment on intentionalia has to be partial, but he draws the line between merely would-be intentionalia and genuine intentionalia at the wrong point. For he takes that the ontologically dividing line runs between nonexistent and existent intentionalia, the latter being the only intentionalia that there really are. Cf. (2001a:26). Yet being a nonexistent intentionale, a characteristic that mobilises a first-order predicate of existence, is again not a genuinely metaphysical category such 
that it can be proved that there really are no things of that kind. One can think both of the possible offspring of certain gametes of Elisabeth I of England and of Philip II of Spain and of the impossible horse which is simultaneously all black and all white; yet their both being nonexistent entities does not $e o$ ipso mean that there are no both things, for there are reasons for admitting the former which are reasons for not admitting the latter. For more on this cf. Author (2006a, 2007).

${ }^{17}$ Cf. Crane (2001a:30). In this respect, Crane reprises what Searle (1983) originally maintained. Like Searle, Crane maintains that whenever it turns out that the intentional object a thought is apparently direct upon is such that there really is no such object, the thought is not really directed upon such object but it rather has a certain intentional content. Yet unlike Searle, Crane's appeal to schematism wants to account for the phenomenology involved in such cases: for the bearer of the thought in question, that thought is about an intentional object, it does not involve an intentional content that bearer is not aware of.

${ }^{18}$ As Crane himself is forced to admit. Cf. (2001a:31-2), (2003).

${ }^{19}$ In point of fact, adverbialism's sustainers usually present this position as a theory that wants to monadically account for the intentionality property in general. In other terms, such sustainers do not draw a distinction between cases of thoughts being about intentional objects and cases of thoughts merely having an intentional content, for they hold that intentionality in general must be thoroughly reconstructed as a monadic property, affecting either thoughts themselves or their bearers. Cf. Kriegel (2007). Yet for my purposes it is enough to consider adverbialism as a theory that wants to account monadically for the mere property of having an intentional content.

${ }^{20}$ For subject-modifier adverbialism, cf. traditionally Ducasse (1942) and Chisholm (1957); thoughtmodifier adverbialism has been defended by Tye (1984) and most recently by Kriegel (2007).

${ }^{21}$ Cf. Kriegel (2007).

${ }^{22}$ Fodor addresses these criticisms against what he labels “the fusion view”. Cf. (1981:179-81).

${ }^{23}$ For this example, cf. originally Twardowski (1982:106).

${ }^{24}$ One might think that "Indy-ly" and "Whack-ly" express noncumulable adverbial modifications; a sentence construed along the lines of (5t-a) such as "S thinks Indy-Whackly" is utterly meaningless. It may be the case that non-cumulability tells a pair like (7)-(8) from sentences like "S thinks intensely" and 
"S thinks loosely", where cumulation is possible: "S thinks intense-loosely" sounds acceptable. (I owe this suggestion to Bill Fish). Let me put aside the problem that it is not clear whether this is the right way to pick up a certain class of sentences (how does the fact that adverbial modifications like those expressed by "Indy-ly" and "Whack-ly" are cumulable have to do with the fact that (7)-(8) intuitively predicate having an intentional content of different intentional states?). It remains that adverbs like "seriously" and "make-believedly" express noncumulable adverbial modifications as well ("S think seriousmakebelievedly” is unacceptable). Alternatively, a thought-modifier adverbialist might try to account for the supposed commonality between the intentional states reported by (7)-(8) in terms of their similarity in inferential role. (I owe this suggestion to Farid Masrour.) For example, by relying perhaps on some meaning postulates, she might try to say that, unlike (9)-(10), (7)-(8) entail that someone cogitates of something. True enough, if there were such a commonality, the thought-modifier adverbialist would have managed to show why, unlike the states reported by (9)-(10), the states reported by (7)-(8) share a general intentionality property. Yet it is hard to show that there is such a commonality once inferences from (7)(8) to the thought that someone cogitates of something are to be blocked for a thought-modifier adverbialist. For if she did not block these inferences, she would have then precisely got the for her unwelcome result that the general intentionality property is relational.

${ }^{25}$ Kriegel (2007) goes precisely in this direction, by maintaining that the monadically reconstructed general intentional property is a phenomenal property which is merely described in adverbialist terms. Let me put aside the fact that this account presupposes at least two controversial premises: first, that all basic intentional states are also phenomenal states; second, that the fact that they are phenomenal is relevant for their also being intentional. The problem with this account is that, as there are various phenomenal characters, there should be a distinct intentionality property for each such character, hence for states endowed with different phenomenal characters. As a result, not only thinking of Indy and waiting for Whack, if they were endowed with distinct phenomenal characters, would not instantiate one and the same allegedly monadic property of having an intentional content, but this would also (and quite counterintutively) hold of, say, the two states of having the impression of seeing Whack and of having the 
impression of hearing Whack, insofar as, again, these two states are endowed with different phenomenal characters.

${ }^{26}$ In this respect, the thought-modifier adverbialist might bite the bullet and say that, unlike further sentences like "S runs seriously", "S’ eats makebelievedly" etc., (7)-(10) all entail that someone cogitates of something. Yet this move is precluded to her again for the reasons I said before: that inference is blocked for a thought-modifier adverbialist.

${ }^{27}$ For an account of being about an object and having an intentional content that make them two different relational intentionality properties, cf. Haldane (1989:18).

${ }^{28}$ This is a particularly welcome result if one also wants to maintain that intentionality is in general (i.e., independently of its subdivisions) at least a dependence relation: cf. on this Author (2005, 2006c).

${ }^{29}$ For this problem, originally raised by Evans (1982) and Walton (1990), as well as for some possible solutions to it, cf. e.g. Kroon (2005), Recanati (2000:chap.15).

${ }^{30}$ For this distinction between the two notions of true-at and true-in, cf. for instance Adams (1981:22).

${ }^{31}$ This example again comes from Twardowski (1982:106).

32 This is the solution implicitly defended by Evans (1982) and Walton (1990), but criticised by Recanati (2000:176,218,250-1).

${ }^{33}$ Cf. Kripke (1980:76-7). Kripke limits himself to make this point as regards reference, but its extension to truthconditions is obvious.

${ }^{34}$ A previous version of this paper has been presented to the Conference on Intentional Objects held at the University of Auckland on 25-26 August, 2007, and at a seminar at the Center for Consciousness, Australian National University, Canberra, November 1, 2007. I thank all the participants to these events for their stimulating remarks. I also thank Uriah Kriegel and Elisabetta Sacchi for their insightful comments. 